УДК 616.15: 612.115

\title{
ИНИЦИАЦИЯ СВЕРТЫВАНИЯ КРОВИ В РАЗНЫЕ СРОКИ ФИЗИОЛОГИЧЕСКИ ПРОТЕКАЮЩЕЙ БЕРЕМЕННОСТИ
}

\author{
Андрей Павлович МОМОТ ${ }^{1}$, Ирина Алексеевна ТАРАНЕНКО ${ }^{1}$, \\ Дмитрий Евгеньевич БЕЛОЗЕРОВ ${ }^{2}$, Людмила Петровна ЦЫВКИНА ${ }^{1}$, \\ Наталья Ильинична ФАДЕЕВА², Марина Викторовна МЕДВЕДЕВА ${ }^{3}$
}

${ }_{1}^{1}$ Алтайский филиал ФГБУ Гематологический научный иентр Минздрава России 656045 , г. Барнаул, ул. Ляпидевского, 1

${ }^{2}$ ГБОУ ВПО Алтайский государственный медицинский университет Минздрава России 656038 , г. Барнаул, пр. Ленина, 40

${ }^{3}$ ООО «Инвитро-Сибирь»

630000, г. Новосибирск, Красный пр., 218/2

Цель исследования - анализ пусковых механизмов активации свертывания крови на разных сроках физиологически протекающей беременности и оценка возможной роли их нарушений для возникновения репродуктивных потерь и преждевременных родов. МАТЕРИАЛ И МЕТОДЫ. Обследована 301 женщина вне беременности, в различные сроки физиологической беременности и на 2-3-е сутки после самопроизвольных родов. В плазме венозной крови устанавливали содержание тканевого фактора (ТФ), активность ингибитора пути тканевого фактора (ИПТФ), уровень активированного фактора VIIa (ФVIIa), фибринопептида А (ФПА) и D-димеров. РЕЗУЛЬТАТЫ И ОБСУЖДЕНИЕ. Определены прогрессирующее нарастание содержания ТФ, динамика и интервалы допустимых значений ТФ и ИПТФ, а также их соотношение в разные сроки физиологической беременности $(r=0,15 ; p<0,03)$. ТФ преобладал над ИПТФ начиная с 12-13 недели, что было наиболее выражено в поздние сроки гестации (34-36 недель). Концентрация ТФ находилась в прямой связи с уровнем $\Phi$ VIIa $(r=0,21$; $p<0,002)$, ФПА $(r=0,23 ; p<0,001)$ и D-димеров $(r=0,40 ; p<0,001)$, что свидетельствовало об успешной реализации коагуляционного потенциала в крови беременных женщин, не сопровождающейся, однако, развитием клинически значимой сосудистой ишемии. Допускается, что высокий уровень ТФ не только способствует активации гемостаза, но и одновременно выступает инициатором завершения беременности и начала родовой деятельности. Материалы статьи определяют пусковые механизмы нарастающей тромбогенности крови при беременности, а полученные данные могут быть использованы в качестве ориентировочных значений для формирования групп риска по тромботическим и акушерским осложнениям.

Ключевые слова: тканевой фактор, ингибитор тканевого пути свертывания, фактор VIIа, фибринопептид A, D-димеры, физиологически протекающая беременность.

При беременности отмечается повышение коагуляционных свойств крови, направленное, как предполагается, на предупреждение фатального кровотечения в родах $[16,30]$. Данный процесс проявляется динамичным увеличением концентрации свидетелей появления в кровотоке тромбина и активации фибринолиза - фибринопептида А (ФПА), комплекса «тромбин - антитромбин», фрагмента протромбина 1+2 и D-димеров [7]. Увеличение уровня маркеров тромбинемии при течении беременности представляет собой финальный результат взаимодействия и противодействия различных звеньев системы гемостаза, обладающих прокоагуляционной, противосвертывающей и фибринолитической активностью. Важно учитывать и то, что при значительном изменении количества и/или активности многих участников гемостатических реакций этот период жизни женщины, как правило, не сопровождается тромбозом или кровотечениями благодаря

Момот A.П. - д.м.н., проф., директор, е-mail: xуzаn@yandex.ru

Тараненко И.А. - к.м.н., научный сотрудник, е-таil: tarania@таil.ru

Белозеров Д.Е. - младший научный сотрудник, e-mail:dmitrbelozerov@yandex.ru

Цывкина Л.П. - д.м.н., проф., старший научный сотрудник, е-mail: katerina-cyvkina@mail.ru

Фадеева Н.И. - д.м.н., проф., директор, e-mail: nat2fad@hotmail.com

Медведева М.В. - врач-лаборант, e-mail: MMedvedeva@sib.invitro.ru 
Момот А.П. и др. Инициация свертывания крови в разные сроки физиологически... /с. 58-66

формированию особенного варианта гемостатического баланса $[1,4,20]$, свойственного не только состоянию беременности, но и периоду новорожденности [26].

Центральное место в системе гемостаза принадлежит тромбину. Развитие в последние годы клеточной модели свертывания крови «іn vivo» определило тканевой фактор (ТФ) как единственный инициатор образования тромбина, попадающий в кровоток при повреждении эндотелия кровеносных сосудов под воздействием провоспалительных цитокинов, эндотоксина, адреналина, гипоксии или значительной кровопотери [17]. ТФ входит в число интегральных мембраносвязанных гликопротеинов и экспрессируется на клетках крови и эндотелии, а также взаимодействует с имеющимся в крови фактором VII (ФVII) с образованием комплекса «ТФ - ФVIІа» (так называемая фаза «инициации» свертывания крови). Данный комплекс способствует образованию в небольших количествах фактора ІІа (тромбина), который затем используется для активации тромбоцитов. В течение следующей фазы свертывания крови - «усиления», тромбин приводит к высвобождению фактора Виллебранда из эндотелия кровеносных сосудов и создает условия для образования активированных факторов V, VIII и XI. На следующей стадии в фазе «распространения» различные факторы и ферменты объединяются на поверхности активированных тромбоцитов для образования комплекса теназы и фактора Ха, вслед за чем происходит массированная продукция тромбина - достаточная для превращения фибриногена в фибрин [18, 28].

Описанный выше процесс в случае низкой, в ряде патологических состояний, активности физиологических антикоагулянтов, ограничивающих распространение свертывания крови, способен приводить к массированному фибринообразованию со всеми известными последствиями критической сосудистой ишемии $[6,24]$.

Процессы активации свертывания крови изучены в большом числе работ, в то же время исследований, посвященных начальным этапам свертывания крови и возможностям мало изученного ингибитора ТФ (ингибитора пути ТФ - ИПТФ, tissue factor pathway inhibitor - TFPI) в сдерживании внутрисосудистого свертывания крови при беременности, крайне мало. Допускается, что избыточная активация на раннних этапах гемокоагуляции может приводить как к тромбозам, так и к клиническим осложнениям во время беременности $[14,15,29]$.

Цель настоящей работы заключалась в анализе пусковых механизмов активации свертывания крови на разных сроках физиологически протека- ющей беременности и оценке возможной роли их нарушений для возникновения репродуктивных потерь и преждевременных родов.

\section{МАТЕРИАЛ И МЕТОДЫ}

В рамках проспективного исследования получены данные о 301 женщине, обследованной в женских консультациях и родильном доме № 2 г. Барнаула. Исследования выполнялись в лаборатории патологии гемостаза КГБУЗ «Краевая клиническая больница» (г. Барнаул) при участии сотрудников Алтайского филиала ФГБУ «Гематологический научный центр» Минздрава России, лаборатории гематологии Центральной научно-исследовательской лаборатории ГБОУ ВПО Алтайский государственный медицинский университет Минздрава России и лаборатории ООО «Инвитро-Сибирь», г. Новосибирск. Представленное исследование было одобрено Локальным этическим комитетом ГБОУ ВПО Алтайский государственный медицинский университет Минздрава России (выписка из протокола № 14 от 11.12.2013), все участники дали свое информированное согласие.

С учетом результатов клинического и лабораторного обследования проводилась консультация акушером-гинекологом, терапевтом и гематологом, после чего решался вопрос о включении женщины на том или ином сроке беременности в настоящее исследование. Учитывались данные у перво- и повторнобеременных в возрасте от 18 до 35 лет. Критерии исключения из исследования, характеристика обследованных женщин и рожденных детей описаны нами ранее [4].

Отобраны следующие контрольные точки для исследования системы гемостаза, учитывающие волны инвазии трофобласта и отражающие «критические» сроки беременности: прегравидарный период, 6-8 недель, 12-13 недель, 22-24 недели, 34-36 недель и 2-3-е сутки после родоразрешения, соответственно 1, 2, 3, 4, 5 и 6 этапы. Все женщины, принятые в исследование, обследовались, как правило, однократно.

Взятие венозной крови осуществлялось из локтевой вены в пробирки VACUETTE с буферным раствором цитрата натрия в соотношении 9:1 (9NC Coagulation sodium citrate 3,2 \%). Кровь центрифугировали при $1400 \mathrm{~g}$ в течение 15 мин при комнатной температуре. Перед проведением иммуноферментных анализов плазму хранили при температуре $-40{ }^{\circ} \mathrm{C}$ в низкотемпературном холодильнике MDF-192 Ultra low temperature freezer (Sanyo, Япония) от одних суток до одного месяца.

Содержание ТФ, активность ИПТФ, активированного фактора VII (ФVIIa) и концентрация 
ФПА и D-димеров в плазме крови изучались с помощью тест-систем соответственно Actichrome ${ }^{\circledR}$ TF, Actichrome ${ }^{\circledR}$ TFPI (Sekisui Diagnostics, American Diagnostica, CШA), AssaySense Human Factor VII Chromo-genic Activity (AssayPro, США) и IMUCLONE FPA ELISA (Sekisui Medical Co., США) на микропланшетном фотометре BioRad 680 (Bio-Rad Laboratories, США). Уровень $\mathrm{D}$-димеров в плазме крови изучался с помощью тест-системы «Auto Red D-dimer 700» (Helena Bioscience, Германия) на автоматическом коагулометре Sysmex CA-1500 (Siemens, Германия).

При выполнении статистического анализа использовался непараметрический критерий Манна - Уитни для двух независимых групп, а также ранговый коэффициент корреляции Спирмена. Статистически значимыми принимались значения при $p<0,05$. Для показателей каждого теста на разных этапах обследования были рассчитаны медиана (Me), среднее значение (X) и референтные интервалы (2,5-97,5 \%о).

\section{РЕЗУЛЬТАТЫ}

Полученные результаты, в целом, проявили нарастающую активацию свертывания крови у беременных по мере увеличения сроков геста-
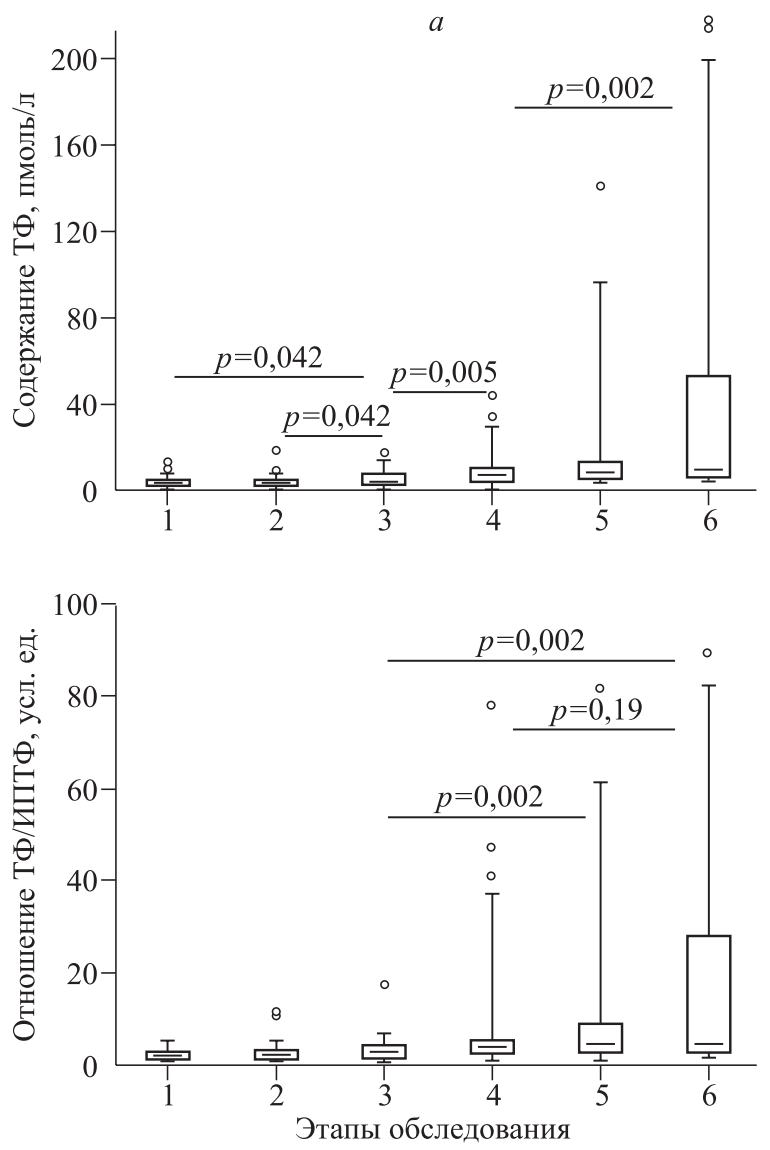

ции, что было продемонстрировано следующими наблюдениями.

В частности, определено увеличение экспрессии ТФ в плазме крови беременных (рис. 1, $a$ ). Можно видеть, что уровень ТФ у женщин вне беременности и родов находился в достаточно широком диапазоне значений (от 1,54 до 11,12 пмоль/л) и практически не менялся на сроке гестации 6-8 недель (табл. 1). В последующем, по мере прогрессирования беременности, наблюдалось увеличение содержания ТФ от исходного уровня (вне беременности) в 1,26, 2,32 и 2,75 раза (по медиане) на 3, 4 и 5 этапах обследования соответственно. Травма, связанная с родоразрешением, сочеталась с наибольшей концентрацией этого ключевого активатора свертывания крови, достигшей у трех из 44 женщин (в 6,8 \% наблюдений) уровня более 200 пмоль/л.

Полученные результаты соответствуют опубликованным ранее данным, согласно которым увеличение коагулирующей активности крови женщин находится на пике своей выраженности в период, близкий к родоразрешению, сопровождающемуся изгнанием плаценты $[2,7,11]$. Как сильный инициатор коагуляции, ТФ быстро приводит к тромбированию сосудов в целях остановки кровотечения у матери в период родов. Это

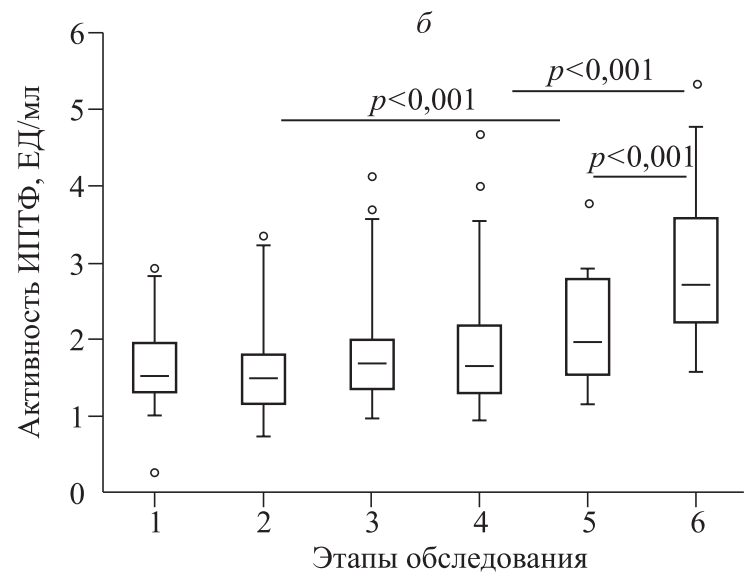

Puc. 1. Динамика содержания ТФ (а), активности ИПТФ (б) и отношения ТФ/ИПТФ (в) в плазме крови у беременных и небеременных женщин. Здесь и на рис. 2 линиями обозначеньл медианы, прямоугольниками - верхний и нижний квартили, «усами» - 95-процентные доверительные интерваль, кружками вығбросы 
Момот А.П. и др. Инициация свертывания крови в разные сроки физиологически... /с. 58-66

Таблица 1

Допустимый диапазон значений содержания ТФ в плазме крови (пмоль/л) в разные сроки физиологической беременности

\begin{tabular}{|c|l|c|c|c|}
\hline $\begin{array}{c}\text { Этап } \\
\text { обследования }\end{array}$ & \multicolumn{1}{|c|}{ Срок беременности } & $\mathrm{Me}$ & $\mathrm{X}$ & Референтный интервал \\
\hline 1 & Вне беременности $(n=50)$ & 2,88 & 3,63 & $1,54-11,12$ \\
\hline 2 & $6-8$ неделя $(n=50)$ & 2,91 & 3,86 & $1,36-9,83$ \\
\hline 3 & $12-13$ неделя $(n=41)$ & 3,64 & 5,44 & $1,55-13,64$ \\
\hline 4 & $22-24$ неделя $(n=55)$ & 6,69 & 8,95 & $2,23-32,53$ \\
\hline 5 & $34-36$ неделя $(n=37)$ & 7,93 & 17,13 & $2,75-100,75$ \\
\hline 6 & На 2-3 сутки после родов $(n=44)$ & 8,93 & 44,99 & $3,96-213,75$ \\
\hline
\end{tabular}

Таблица 2

Допустимый диапазон значений активности ИПТФ (ед./мл) в разные сроки физиологической беременности

\begin{tabular}{|c|l|c|c|c|}
\hline $\begin{array}{c}\text { Этап } \\
\text { обследования }\end{array}$ & \multicolumn{1}{|c|}{ Срок беременности } & Me & Х & Референтный интервал \\
\hline 1 & Вне беременности $(n=48)$ & 1,58 & 1,79 & $1,07-2,99$ \\
\hline 2 & $6-8$ неделя $(n=50)$ & 1,50 & 1,62 & $0,75-3,33$ \\
\hline 3 & $12-13$ неделя $(n=43)$ & 1,68 & 1,80 & $0,85-3,69$ \\
\hline 4 & $22-24$ неделя $(n=55)$ & 1,66 & 1,90 & $0,95-3,84$ \\
\hline 5 & $34-36$ неделя $(n=35)$ & 1,96 & 2,04 & $1,13-3,06$ \\
\hline 6 & $2-3$ сутки после родов $(n=45)$ & 2,72 & 2,95 & $1,54-5,18$ \\
\hline
\end{tabular}

представляется весьма важным, поскольку при плацентарном токе крови 700 мл/мин может произойти сильное кровотечение, если система коагуляции не справится со своей задачей [22].

Учитывая принцип «равновесия и противодействия», касающийся протеолитических систем крови и проявляющийся формированием неактивных комплексов, таких как «тромбин - антитромбин», «плазмин - антиплазмин», «тканевой активатор плазминогена - ингибитор тканевого активатора плазминогена 1 типа» и ряда других, представлялось важным также описание динамики ИПТФ во время беременности. Как известно, ИПТФ относится к ингибиторам протеиназ типа Кунитца и обладает двумя важными доменами ингибирующим комплекс «ТФ - ФVIІа» и инактивирующим фактор Ха [10]. Он вырабатывается преимущественно эндотелием сосудов легких и плаценты, а 90 \% его пула находится в крови в комплексе с липопротеинами низкой и высокой плотности [21]. Для изучения антикоагулянтного действия данного ингибитора в современной практике используют определение общей активности ИПТФ, учитывающей последствия образования и активности поликомпонентного комплекса «ТФ - ФVIIа - ФХа - ИПТФ». Результаты такой оценки в период, предшествующий бере- менности и в различные ее сроки, приведены на рис. $1, \sigma$.

В соответствии с полученными результатами активность ИПТФ при беременности возрастала, но менее значительно по сравнению с темпами увеличения содержания ТФ. Корреляция между ТФ и ИПТФ была сравнительно слабой $(r=0,15$, $p<0,03)$. Умеренный рост активности ИПТФ зафиксирован лишь на 5 и 6 этапах исследования (по медиане соответственно на 24,0 и $72,2 \%$, в сравнении результатами, полученными до наступления беременности) (табл. 2). Отметим также, что нами не было найдено увеличения активности ИПТФ в плазме крови женщин в первой половине беременности, определенное в работе G. Sarig et al. [27]. Однако приведенные данные соответствуют результатам, опубликованным M. Uszynski et al. [29], которые установили явный рост активности ИПТФ во время родоразрешения и в первые дни после этого события.

Далее была проведена оценка отношения содержания ТФ и активности его антагониста ИПТФ (рис. 1, в), показавшая его увеличение начиная со второй половины беременности, что наиболее явно проявило себя вскоре после родов. В частности, исследуемое отношение повышалось относительно исходного (до наступления 
Таблица 3

Отношение ТФ/ИПТФ в разные сроки физиологической беременности

\begin{tabular}{|c|l|c|c|c|}
\hline $\begin{array}{c}\text { Этап } \\
\text { обследования }\end{array}$ & \multicolumn{1}{|c|}{ Срок беременности } & Me & X & $\begin{array}{c}\text { Референтный интервал } \\
(2,5 \text { и 97,5 \%о) }\end{array}$ \\
\hline 1 & Вне беременности $(n=45)$ & 1,96 & 2,37 & $0,75-7,77$ \\
\hline 2 & $6-8$ неделя $(n=47)$ & 1,94 & 2,67 & $0,81-10,01$ \\
\hline 3 & $12-13$ неделя $(n=40)$ & 2,75 & 3,51 & $0,79-7,60$ \\
\hline 4 & $22-24$ неделя $(n=54)$ & 3,90 & 7,01 & $1,15-42,91$ \\
\hline 5 & 34-36 неделя $(n=35)$ & 4,45 & 12,05 & $1,31-64,16$ \\
\hline 6 & $2-3$ сутки после родов $(n=41)$ & 4,52 & 19,85 & $1,52-88,97$ \\
\hline
\end{tabular}

беременности) в $1,40,1,99,2,27$ и 2,31 раза (по медиане) и в $1,48,2,96,5,08$ и 8,37 раза (по среднему арифметическому) соответственно на $3,4,5$ и 6 этапах обследования (табл. 3).

Учитывая вышеизложенное, можно было бы ожидать схожей динамики продукции ФVIIa. Действительно, в наших наблюдениях активация этого ключевого фактора свертывания крови имела место, но неожиданным явилось то, что она опережала события и с 3-го этапа исследований имела максимальные значения по сравнению с данными всего периода исследований (рис. 2, a). На 12-13 неделе беременности активность ФVIIa скачкообразно увеличивалась (по медиане на

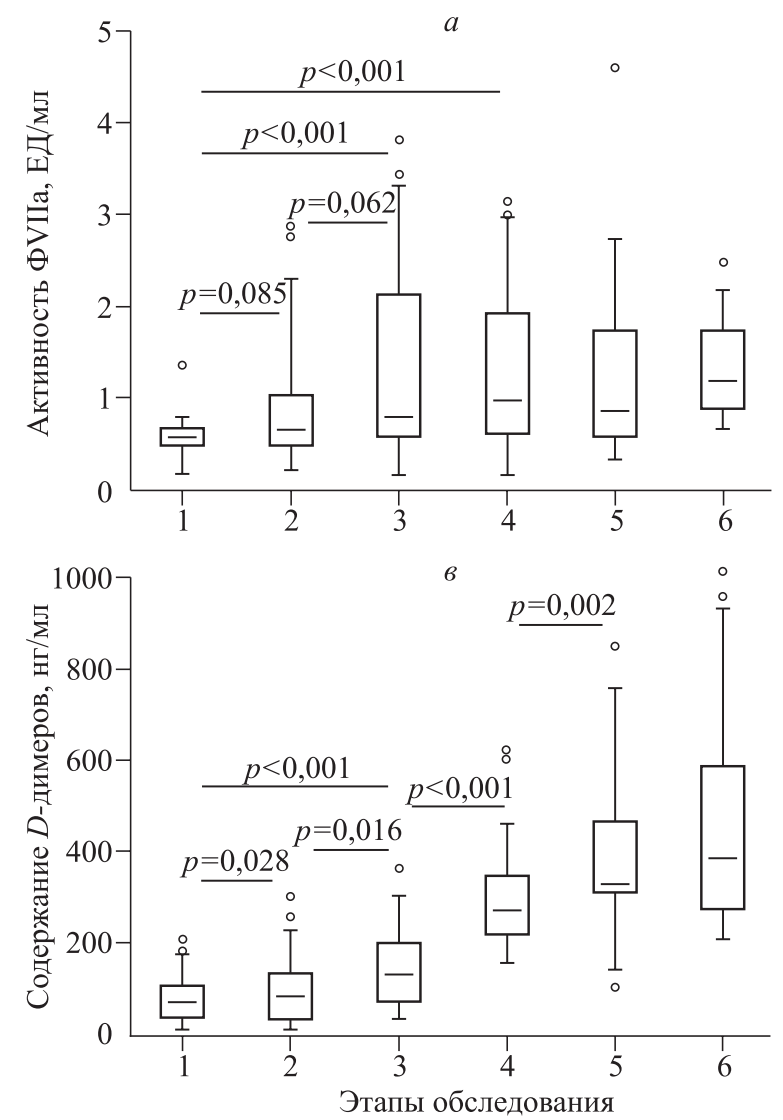

41,1 \% по сравнению со значением до беременности) и оставалась на стабильно высоком уровне вплоть до родоразрешения. Коэффициент корреляции Спирмена, рассчитанный по первым пяти этапам обследования, между содержанием ТФ и активностью ФVIIа составил 0,21 $(p<0,002)$.

Главным следствием инициации свертывания крови считается образование фактора IIа (тромбина) - фермента, обладающего широким спектром действия, но прежде всего - осуществляющего превращение фибриногена в фибрин. Измерить количество тромбина в крови не представляется возможным, поскольку время его активной жизни составляет от нескольких секунд

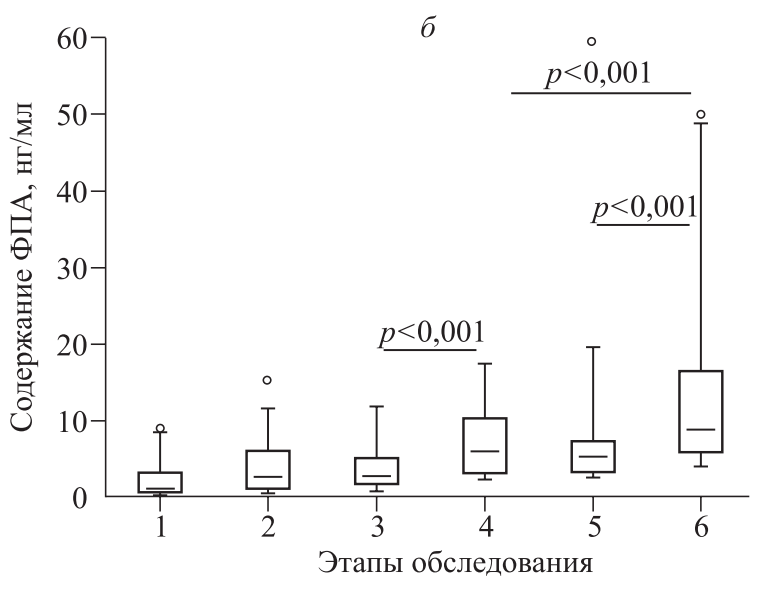

Puc. 2. Динамика активности фактора VIIa (a), содержания ФПА (б) и D-димеров (в) в плазме крови у беременных и небеременных женщин 
до нескольких минут вследствие связывания с антитромбином III и тромбомодулином. В этих целях обычно определяют некоторые свидетели присутствия тромбина в кровотоке [5], в настоящем исследовании были изучены два из них ФПА и D-димеры. ФПА представляет собой пептид с молекулярной массой 1536 Да, состоящий из 16 аминокислотных остатков $\mathrm{N}$-концевого участка $A \alpha$-цепи фибриногена и образующийся при протеолитическом действии тромбина. Он относится к прямым, коротко живущим маркерам тромбинемии [9].

В наших исследованиях уровень ФПА имел тенденцию к росту наряду с увеличением сроков гестации, о чем свидетельствуют данные, приведенные на рис. 2, б. При этом очевидно, что увеличение концентрации ФПА наблюдалось уже с 6-8 недель беременности (по медиане в 2,1 раза) и было достоверно значимым начиная с 4 этапа исследований (22-24 недели). Максимальный уровень ФПА совпадал по времени с первыми днями после родоразрешениея и превышал (по медиане) исходные значения до беременности в 6,4 раза. В дополнение к этому отметим наличие корреляционной связи между содержанием в плазме крови ФПА и ТФ $(r=0,23 ; p<0,001)$, ФПА и ФVIIa $(r=0,32 ; p<0,001)$, ФПА и соотношением ТФ/ИПТФ $(r=0,19 ; p=0,02)$.

К другим высокоинформативным маркерам тромбинемии, как известно, относятся D-димеры. Увеличение содержания D-димеров во время беременности, как считается, может отражать повышенную активацию коагуляции и тромбинообразования, повышенный фибринолиз или сочетание того и другого. Сегодня тестирование на D-димеры во время беременности достаточно широко рекомендуется для диагностики и прогнозирования венозных тромбоэмболических осложнений или связанных с беременностью осложнений, а также для мониторинга антитромботической терапии $[3,7,13]$. По результатам проведенных исследований установлено нарастание данного маркера при увеличении сроков беременности, и этот рост был наиболее динамичен в сравнении с другими показателями свертываемости крови, изученными в настоящей работе (рис. 2, в). В частности, зафиксировано увеличение данных (по медиане) на 6-8 неделе беременности на $18 \%$, на $12-13$ неделе - на $86 \%$, на 22-24 неделе - в 3,84 раза и в конце срока вынашивания беременности - в 4,68 раза. Эти результаты близки к имеющимся в литературе. В соответствии с данными J. Kline et al. [23], уровень D-димеров возрастает по срокам гестации и ко времени родоразрешения может превышать обычный, определяемый вне беременности, в 3-4 раза. Однако в рамках проведенного исследования нас прежде всего интересовала связь между реакциями инициации свертывания крови и свершившимися событиями образования фибрина. Согласно проведенному анализу установлена корреляционная связь между концентрацией D-димеров и ТФ $(r=0,40 ; p<0,001)$, D-димеров и ФVIIa $(r=0,22$; $p=0,001)$, D-димеров и соотношением ТФ/ИПТФ $(r=0,25 ; p<0,001)$.

\section{ОБСУЖДЕНИЕ}

В работе установлен значительный рост содержания ТФ при приближении к срокам родоразрешения, хотя достоверно значимое увеличение этого показателя было зафиксировано уже с 12-13 недели беременности. Целесообразность такого раннего повышения концентрации ТФ не вполне понятна, поскольку роды и, соответственно, ограничение объема кровопотери в первой половине беременности не запрограммированы природой. С другой стороны, трудно допустить, что резкое, скачкообразное повышение тромбогенности крови перед родами может обойтись без системных и фатальных проявлений сосудистой ишемии. Как известно, ТФ входит в число интегральных мембраносвязанных гликопротеинов клеток эндотелия и лейкоцитов. Он является важным кофактором факторов VII и VIIa, инициирует свою прокоагулянтную активность на поверхности клеток и попадает в кровоток обычно при повреждении эндотелия кровеносных сосудов и при стимуляции лейкоцитов под воздействием провоспалительных цитокинов, эндотоксина, адреналина, гипоксии и/или значительной кровопотери.

Комплекс «ТФ - ФVIIа» способен активировать как фактор X, так и фактор IX, приводя к реализации известных механизмов свертывания крови [12]. Установлено, что по сравнению с показателями при физиологически протекающей беременности концентрация ТФ обычно выше в плазме крови матерей с преэклампсией или в случае раннего излития околоплодных вод, но ниже при рождении ребенка с недостаточной массой для данного гестационного возраста, что косвенно может свидетельствовать о его преимущественно плацентарном происхождении [15, 25]. Как отмечалось ранее, в противовес ТФ выступает его ингибитор ИПТФ, синтез которого способен увеличиваться в 5-10 раз эндотелием кровеносных сосудов на фоне приема низкомолекулярных гепаринов [19]. В нашем исследовании ТФ явно преобладал над ИПТФ начиная с 22-24 недели физиологически протекающей беременности. В дополнение к сказанному отметим, что 
согласно имеющимся данным активность ИПТФ в плазме крови беременных женщин повышена при преэклампсии (относительно допустимых значений при физиологической беременности), но снижена при преждевременных родах, раннем излитии околоплодных вод и не меняется у женщин с гипотрофией новорожденного ребенка $[8,14,15]$. Наконец, увеличение содержания ТФ соответственно сроку гестации при одновременно сниженной активности ИПТФ связывается как с усиленной генерацией тромбина, так и высокой вероятностью преждевременных родов [15]. Эти данные и послужили основанием для проведения в настоящей работе расчетов соотношения содержания ТФ и активности ИПТФ в системном кровотоке, которое возрастало пропорционально гестации, очерчивая границы уникального гемостатического баланса на разных сроках беременности.

Важно подчеркнуть, что в предродовый период срочных родов максимально выраженная секреция ТФ в сравнении с активностью его ингибитора, несмотря на прогрессирующее увеличение активности ФVIIа и содержания маркеров тромбинемии ФПА и D-димеров, не приводит к патологическому фибринообразованию, опасному для жизни матери и ребенка, однако эти изменения эффективно контролируют объем материнской кровопотери в родах.

Можно полагать, что высокий уровень ТФ, сопровождающийся нарастанием концентрации известных маркеров тромбинемии, выступает инициатором не только внутрисосудистого свертывания крови, но и завершения беременности, а также начала родовой деятельности. Доказательство этого положения с учетом данных многочисленных публикаций о связи нарушений в системе свертывания крови с бесплодием и осложнениями беременности (ранних выкидышей, синдрома задержки внутриутробного роста плода, преэклампсии, преждевременной отслойки нормально расположенной плаценты, тромбозов, антенатальной гибели плода, преждевременных родов, мертворождения), позволит охарактеризовать важную в числе классических, ранее не выделявшуюся репродуктивную функцию системы гемостаза.

\section{ЗАКЛЮЧЕНИЕ}

Полученные данные определяют пусковые механизмы нарастающей тромбогенности крови при прогрессировании беременности и могут быть использованы в качестве ориентировочных значений для формирования групп риска по тромботическим и акушерским осложнениям.

\section{СПИСОК ЛИТЕРАТУРЫ}

1. Бииадзе В.О., Макачария А.Д., Хизроева Д.Х. $u$ дp. Тромбофилия как важнейшее звено патогенеза осложнений беременности // Практич. мед. 2012. (5). 22-29.

2. Бышевский А.Ш., Полякова В.А., Рудзевич А.Ю. Гемостаз при физиологической беременности, беременности с артериальной гипертензией и преэклампсией // Тромбоз, гемостаз и реология. 2010. 4. (44). 13-30.

3. Гильманов А.Ж. D-димер: Что? Как? У кого? C какой целью? // Клинич. лабораторн. консилиум. 2009. 6. (31). 38-46.

4. Момот А.П., Кирющенков П.А., Трухина Д.А. $u$ др. Референтные значения уровня и активности фактора Виллебранда, металлопротеиназы ADAMTS-13, активности тромбоцитов при физиологически протекающей беременности // Акушерство и гинекология. 2014. (2). 46-52.

5. Момот А.П., Цьвкина Л.П., Тараненко И.А. и $\partial p$. Современные методы распознавания состояния тромботической готовности / Ред. А.П. Момот. Барнаул: Изд-во АГУ, 2011. 138 с.

6. Шойхет Я.Н., Момот А.П., Ельккомов В.А. К обоснованию новой технологии негепаринового усиления антикоагулянтных свойств свежезамороженной плазмы при заместительной гемокомпонентной терапии синдрома диссеминированного внутрисосудистого свертывания крови // Пробл. клинич. мед. 2008. (5-6). 130-144.

7. Abbassi-Ghanavati M., Greer L.G., Cunningham F.G. Pregnancy and laboratory studies: a reference table for clinicians // Obstet. Gynecol. 2009. 114. 13261331.

8. Abdel Gader A.M., Al-Mishari A.A., Awadalla S.A. et al. Total and free tissue factor pathway inhibitor in pregnancy hypertension // Int. J. Gynaecol. Obstet. 2006. 95. 248-253.

9. Amiral J., Walenga, J.M., Fareed J. Development and performarnance characteristics of a competitive enzyme immunoassay for fibrinopeptide A // Semin. Thromb. Hemost. 1984. 10. 228-242.

10. Broze G.J. Jr, Girard T.J., Novotny W.F. Regulation of coagulation by a multivalent Kunitz-type inhibitor // Biochemistry. 1990. 29. 7539-7546.

11. Carson S.D., Ramsey C.A. Tissue factor (coagulation factor III) is present in placental microvilli and cofractionates with microvilli membrane proteins // Placenta. 1985. 6. (1). 5-12.

12. Edgington T.S., Mackman N., Brand K. et al. The structural biology of expression and function of tissue factor // Thromb. Haemost. 1991. 66. (1). 67-79.

13. Eichinger $S$. D-Dimer testing in pregnancy // Pathophysiol. Haemost. Thromb. 2003/2004. 33. 327329.

14. Erez O., Hoppensteadt D., Than N.G. Tissue factor and its natural inhibitor in preeclampsia and 
SGA // J. Matern. Fetal. Neonatal. Med. 2008. 21. 855859.

15. Erez O., Romero R., Vaisbuch E. et al. High tissue factor activity and low tissue factor pathway inhibitor concentrations in patients with preterm labor // J. Matern. Fetal. Neonatal. Med. 2010. 23. (1). 23-33.

16. Hale S.A., Schonberg A., Badger G.J. et al. Relationship between prepregnancy and early pregnancy uterine blood flow and resistance index // Reprod. Sci. 2009. 16. (11). 1091-1096.

17. Heit $J$. Thrombophilia: clinical and laboratory assessment and management // Consultative Hemostasis and Thrombosis / Eds. C.S. Kithens, C.M. Kessler, B.A. Konkle. 3rd ed. Philadelphia: Saunders Elsevier, 2013. 205-239.

18. Hoffman $M$. Remodeling the blood coagulation cascade // J. Thromb. Thrombolysis. 2003. 16. (1-2). 17-20.

19. Hoke M., Kyrle P.A., Minar E. et al. Tissue factor pathway inhibitor and the risk of recurrent venous thromboembolism // Thromb. Haemost. 2005. 94. 787-790.

20. Holmes V.A., Wallace J.M. Haemostasis in normal pregnancy: a balancing act? // Biochem. Soc. Trans. 2005. 33. (2). 428-432.

21. Hube F., Reverdiau P., Iochmann S. et al. Demonstration of a tissue factor pathway inhibitor 2 messenger RNA synthesis by pure villous cytotrophoblast cells isolated from term human placentas // Biol. Reprod. 2003. 68. 1888-1894.

22. Kelley C.M., Bernstein I.M., Brummel-Ziedins $K$. Tissue factor dependent thrombin generation across pregnancy // Am. J. Obstet. Gynecol. 2012. 207. (2). $135 \mathrm{e} 1-135 \mathrm{e} 6$.

23. Kline J., Williams G., Hernandez-Nino J. D-Dimer concentrations in normal pregnancy: New diagnostic thresholds are needed // Clin. Chem. 2005. 51. (5). 825-829.

24. Levi $M$. The coagulant response in sepsis and inflammation // Hamostaseologie. 2010. 30. (1). 10-12, $14-16$.

25. Lockwood C.J., Krikun G., Caze R. et al. Decidual cell-expressed tissue factor in human pregnancy and its involvement in hemostasis and preeclampsia-related angiogenesis // Ann. N. Y. Acad. Sci. 2008. 1127. 67-72.

26. Monagle P., Barnes $C$., Ignjatovic $V$. et al. Developmental haemostasis. Impact for clinical haemostasis laboratories // Thromb. Haemost. 2006. 95. (2). 362-372.

27. Sarig G., Blumenfeld Z., Leiba $R$. et al. Modulation of systemic hemostatic parameters by enoxaparin during gestation in women with thrombophilia and pregnancy loss // Thromb. Haemost. 2005. 94. 980-985.

28. Smith S.A. The cell-based model of coagulation // J. Vet. Emerg. Crit. Care. 2009. 19. (1). 3-10.

29. Uszynski M., Zekanowska E., Uszynski W. et al. Tissue factor (TF) and tissue factor pathway inhibitor (TFPI) in amniotic fluid and blood plasma: implications for the mechanism of amniotic fluid embolism // Eur. J. Obstet. Gynecol. Reprod. Biol. 2001. 95. 163166.

30. Walfish M., Neuman A., Wlody D. Maternal haemorrhage // Br. J. Anaesth. 2009. 103. (1). i47-i56. 


\title{
INITIATION OF BLOOD COAGULATION IN DIFFERENT STAGES OF NORMAL PREGNANCY
}

\author{
Andrey Pavlovich MOMOT'1, Irina Alekseyevna TARANENKO', \\ Dmitriy Yevgenyevich BELOZEROV ${ }^{2}$, Lyudmila Petrovna TSYVKINA ${ }^{1}$, \\ Natalya Ilyinichna FADEEVA ${ }^{2}$, Marina Viktorovna MEDVEDEVA ${ }^{3}$ \\ ${ }^{1}$ Altai Affiliation of Hematology Research Center of Minzdrav of Russia \\ 656045, Barnaul, Lyapidevskogo str., 1 \\ ${ }^{2}$ Altai State Medical University of Minzdrav of Russia \\ 656038, Barnaul, Lenina av., 40 \\ ${ }^{3}$ «Invitro-Sibir» LTD \\ 630000, Novosibirsk, Krasnyi av., 218/2
}

The purpose of the study was to analyse triggering mechanisms of blood coagulation activation in different stages of normal pregnancy and assessment of the possible role of their disorders for reproductive loss and preterm delivery. Materials and methods. 301 women were examined: non-pregnant women, women in different periods of normal pregnancy and on the 2-3rd day after spontaneous labor. Activity of tissue factor (TF), tissue factor pathway inhibitor (TFPI), the level of activated factor VIIa (FVIIa), fibrinopeptide A (FPA) and D-dimers were determined in venous blood plasma. Results and Discussion. Progressive increase in the activity of TF, the dynamics and intervals of TF and TFPI valid values, as well as the ratio of their activity at different stages in normal pregnancy $(r=0.15 ; p<0.03)$ were defined. TF activity prevailed over TFPI activity ranging from 12-13 weeks, which was more significant in the later stages of gestation (34-36 weeks). TF activity value was directly related to the level of FVIIa $(r=0.21 ; p<0.002)$, FPA $(r=0.23$; $p<0.001)$ and D-dimers $(r=0.40 ; p<0.001)$, indicating the successful implementation of coagulation potential in the blood of pregnant women which is not accompanied, however, by the development of clinically significant vascular ischemia. It is assumed that the high level of TF contributes not only to the activation of hemostasis, but also initiates termination of pregnancy and the onset of labor. Materials of the article define triggering mechanisms of increasing thrombogenicity of blood during pregnancy, and the data can be used as indicative values for the formation of groups at risk for thrombotic and obstetric complications.

Key words: tissue factor, tissue inhibitor of coagulation pathway, factor VIIa, fibrinopeptid A, D-dimers, physiological pregnancy.

Momot A.P. - doctor of medical sciences, professor, director,e-mail: xyzan@yandex.ru

Taranenko I.A. - candidate of medical sciences, researcher, e-mail: tarania@mail.ru

Belozerov D.Ye. - junior researcher, e-mail: dmitrbelozerov@yandex.ru

Tsyvkina L.P. - doctor of medical sciences, professor, senior research, e-mail: katerina-cyvkina@mail.ru

Fadeeva N.I. - doctor of medical sciences, professor, head of the department of obstetrics and gynecology № 1, e-mail:nat2fad@hotmail.com

Medvedeva M.B. - doctor-laboratorian, e-mail: MMedvedeva@sib.invitro.ru 